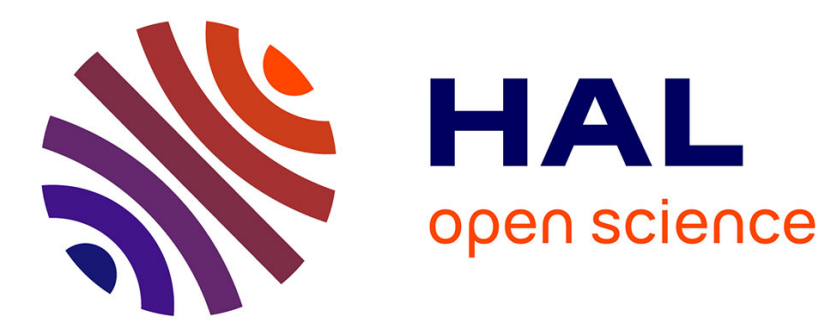

\title{
Power Drive Investigation by Spectral Analysis of the Electromagnetic Field Emitted by the DC Bus
}

\author{
Cyrille Gillot, Hamed Yahoui, Gérard Rojat
}

\section{To cite this version:}

Cyrille Gillot, Hamed Yahoui, Gérard Rojat. Power Drive Investigation by Spectral Analysis of the Electromagnetic Field Emitted by the DC Bus. 32nd IEEE IECON, Nov 2006, Paris, France. pp.5023 - 5026, 10.1109/IECON.2006.348009 . hal-00369576

\section{HAL Id: hal-00369576 https://hal.science/hal-00369576}

Submitted on 3 Jun 2009

HAL is a multi-disciplinary open access archive for the deposit and dissemination of scientific research documents, whether they are published or not. The documents may come from teaching and research institutions in France or abroad, or from public or private research centers.
L'archive ouverte pluridisciplinaire HAL, est destinée au dépôt et à la diffusion de documents scientifiques de niveau recherche, publiés ou non, émanant des établissements d'enseignement et de recherche français ou étrangers, des laboratoires publics ou privés. 


\title{
Power Drive Investigation by Spectral Analysis of the Electromagnetic Field Emitted by the DC Bus
}

\author{
Cyrille Gillot, Hamed Yahoui and Gerard Rojat \\ Laboratoire CEGELY-AMPERE UMR CNRS 5005 \\ Universite Claude Bernard LYON1 \\ Batiment Omega, 43 Bd du 11 Novembre 1918, 69100 Villeurbanne, FRANCE \\ \{gillot, yahoui, rojat\}@cegely.univ-lyon1.fr
}

\begin{abstract}
Induction machine is widely used in industrial applications, and currently numerous researches deals with its on line monitoring. A great on line monitoring would provide fault diagnosis, optimal use and quality management. However, diagnosis is, until today, mainly based on vibration analysis and/or motor current signature analysis (weel known as MCSA). This paper presents a new approach in the whole electrical drive diagnosis thought original measurements. The first part shows that the measures of the electromagnetic field emitted on the DC bus bar of the inverter can provide a relevant signature for the spectral analysis of the power drive. The second part deals with the in sight simulation prospectives, through the widely spread Partial Element Equivalent Circuit (PEEC) modelling of the surfacic conductor structures.
\end{abstract}

\section{INTRODUCTION}

$\mathrm{T}$ HE asynchronous motors are widely spreads in industrial applications, and recent developments in power electronics and electrical drives has lead to a constantly increasing of this electromechanical solution. Therefore, in spite of their robustness, various electrical stress can occur. And even if solutions for the diagnosis of the induction machine are industrially applied nowadays (see [1], [2], [3], [4], and [5], this is a non exhaustive list of course !), it lacks a widely and all-bench - all the electrical and mechanical elements, from the global supply until the load - default diagnosis, treated with a single-diagnosismethod solution. This paper makes the point on original measurements devoted at term for the whole bench diagnosis.

The first part of this paper presents the ideas and reminds the mains results obtained until today with such measures. A huge amounts of significant signal signature has been found with only one non-optimised measure. The second part presents a possible way for the modelling of the DC bus bar and thus a modelling of the complex electromagnetic (EM field, and more precisely the magnetic field) phenomenon on its surface. This last point is very important as the widely employed Finite Elements Methods (FEM) modelling presents some shortcomings when used for surfacic 3D thin conductors. That is unfortunately the case of the inverter bus bar conductors treated in this paper.

\section{DC Bus Bar Magnetic Field Measurements: THE MAINS IDEAS KEYS}

The Fig. 1 presents an electrical drive as used today. One notes that all the power transit throught the DC bus bar of the inverter [6] [7] [8]. Not only probants signals signatures ao the electrical elements must be presents on this bus, but also signals signature of the non-electricals elements (drives, mechanicals elemenst, load...). As on a first estimation, the voltage $\mathbf{u}_{D C}$ bus $(t)$ of the bus can be regarded as constant, thus the instantaneous power $\mathbf{p}_{D C \text { bus }}(t)$ that flow through the DC bus is :

$$
\mathbf{p}_{D C \text { bus }}(t)=\mathbf{u}_{D C \text { bus }}(t) . \mathbf{i}_{D C \text { bus }}(t)
$$

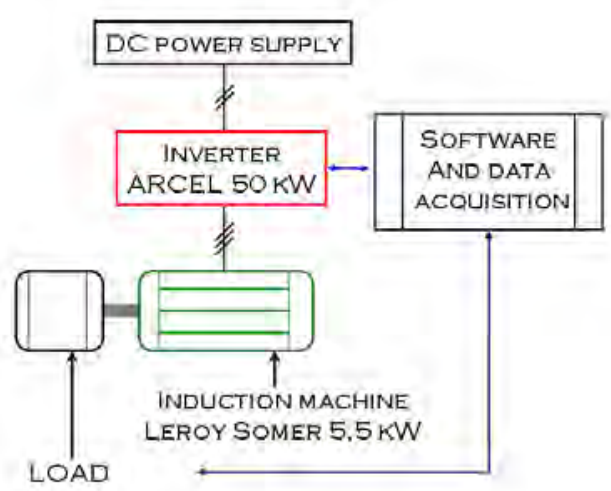

Fig. 1. Synopsis of a classic electrical drive of some dozen of kW.

With $\mathbf{u}_{D C \text { bus }}(t)=$ Constant $=\mathbf{U}$, the DC bus bar current is then an image of the instantaneous power. Unfortunately, due to its very complex geometrical structure, it remains very hard to extract directly the currents lines of the conductors, and an indirect means of measurements must be implemented. 
The key ideas are to work with the magnetic field presents on the surface of the bus. The surfacic magnetic field is also an image of the currents lines, and then probants signal signatures presents in the instantaneous power would be presents too in this surfacic magnetic field. Thus, works has been leads on the DC bus bar of a $50 \mathrm{~kW}$ inverter bus, shown in the Fig. 2. The Fig. 3 presents the negative DC bus bar that is a thin conductive plate with numerous connectors. An Hall effect probe is placed in the bottom mark of this figures, so as to measure the normal magnetic field, concentrated by this particular geometry. The Fig. 4 and the Fig. 5 explains in more details the measurements.

More specifically the Fig. 5 explains the geometrical concentration of the currents lines in the corner. This configuration leads to an increasing magnetic field generation, and hence a great signal amplification. Not only the ration signal-on-noise is better, but the spatial localization of the magnetic field probe intrinsically select a particular part of the signal spectrum - act as a passive filter. One can understand the immense interest which represents such a geometrical selectivity. With selected emplacements of the probe, the signatures of the induction machine either the load can be advanced for example.

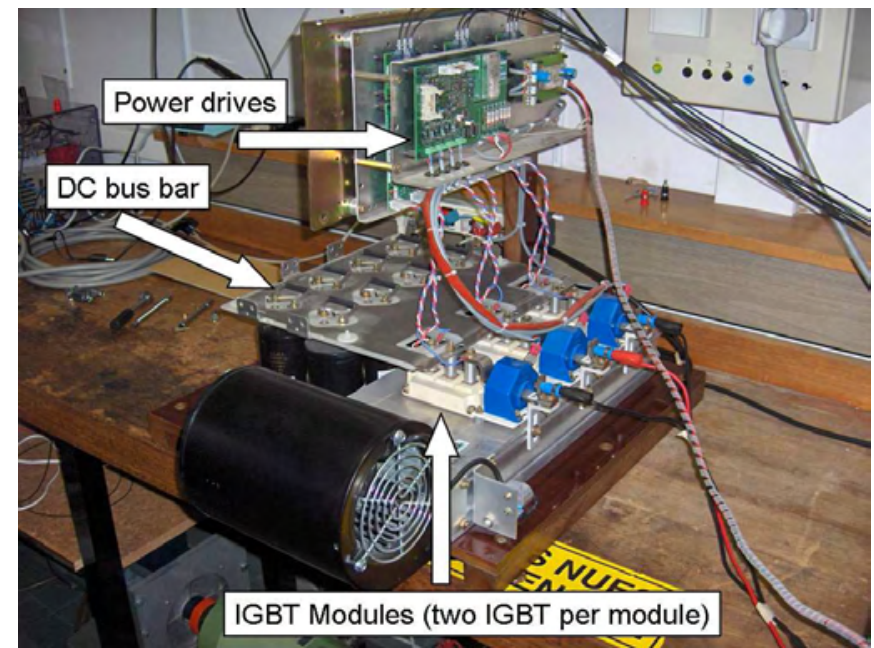

Fig. 2. Presentation of the $50 \mathrm{~kW}$ inverter. The power drives are supplied with an ASIC component not present on this figure.

Thus, the measures in the $0-10 \mathrm{kHz}$ frequency range, on the localization showed in the Fig. 4 and the Fig. 5, have proven to be useful. Signal signature of the PWM drives and the induction motor has been found in the spectrum of the magnetic field. Moreover, signature of the sinusoidal low-frequency load ([9]) has been perfectly visible in this spectrum. So as to push this method on the wall, slot harmonics has also been successfully find, even if this frequency signature are known to be very small (with a ratio signal-on-noise very small i.e. near $2-5$ ).

However, the Hall effect probe frequency range is un-

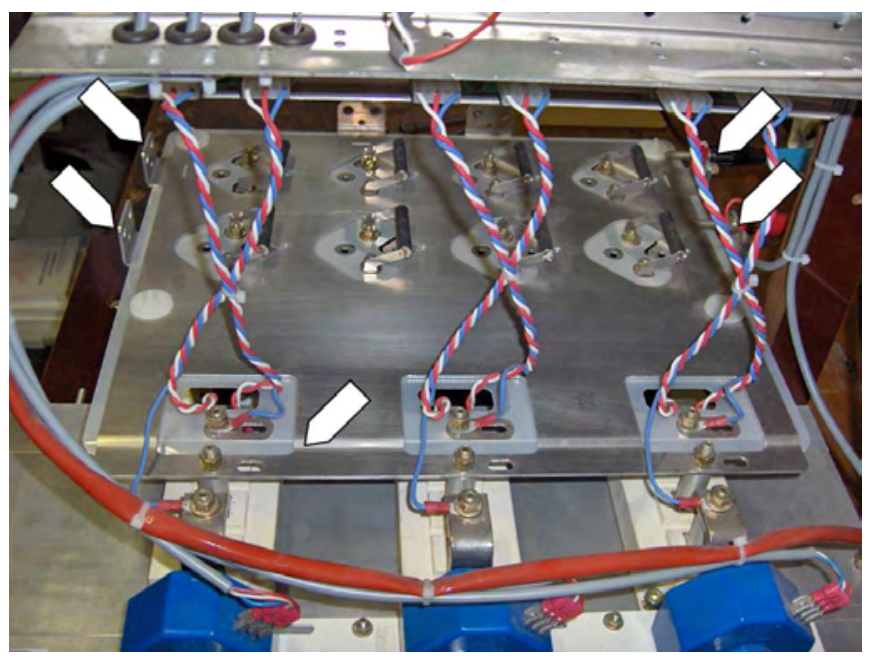

Fig. 3. The DC inverter bus bar. This figure shows particularly the negative DC bus, with all the holes for the different connectors. The marks presents on the top of the conductor are the continuous supply connectors (here the DC bus is connected on the right of the figure). One interesting emplacement for the Hall probe is represented by the mark at the bottom of the bus.

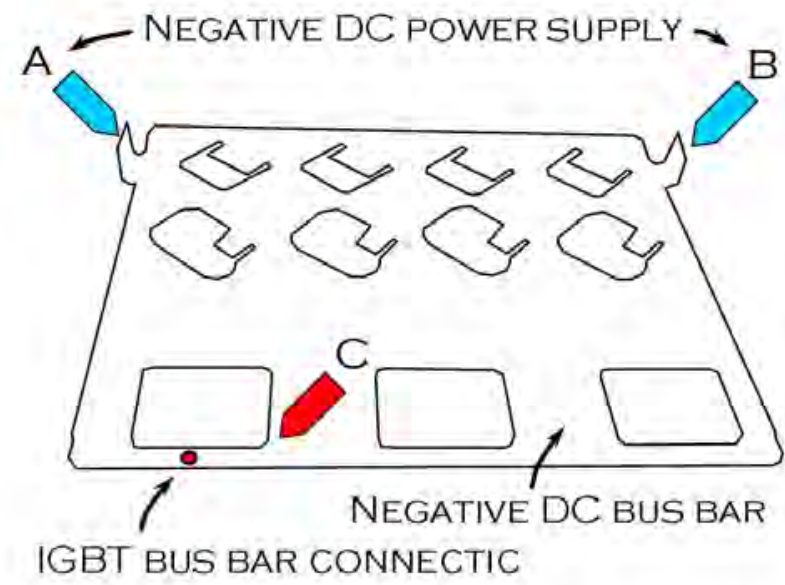

Fig. 4. Graphic representation of the negative DC bus with the two possible DC voltage supply connectors (A or B), and the Hall probe emplacement (in C), near of the IGBT bus bar connector.

fortunately limited because of the differential amplification and all electronic treatment of the signal. So as to grow up in frequency, studies has to benn lead with specific probes, like the emf probes. These probes can extract a sinusoidal magnetic field from $10 \mathrm{kHz}$ until $100 \mathrm{MHz}$ if well calibrated. At these frequencies, the switching elements could be visible, and for instance some acceleration in the IGBT opening sequence could indicate some ageing of the static power electronics.

So, all these observations affable to look for a reliable means of the bus bar modelling as an electromagnetic field radiant structure. The next section proposes to employ the Partial Element Equivalent Structure because of its specific advantages in thin conductors' low-to-high fre- 


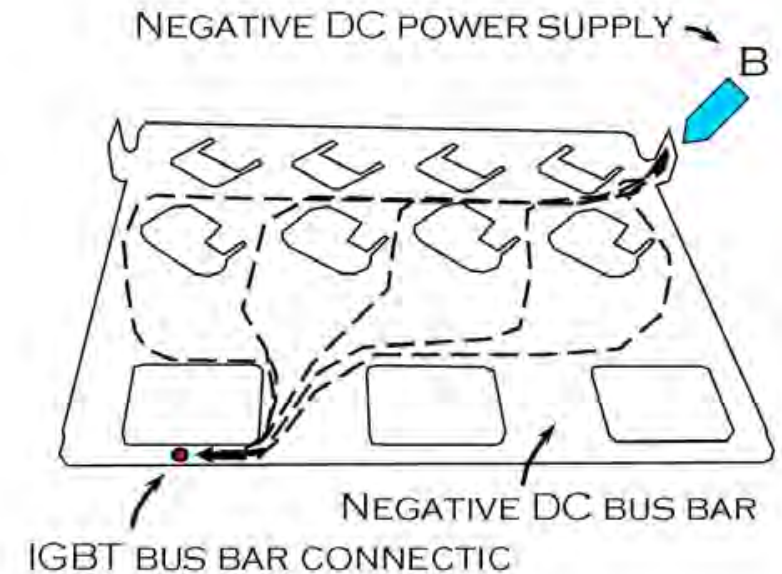

Fig. 5. Possible currents lines on the bus and their concentration near the IGBT connector. This concentration makes the local magnetic field increasing and also makes the probe measurements easier.

quency EMF modelling.

\section{The Partial Element Equivalent Circuit (PEEC) MODEL: THE ISSUE TO THE BUS BAR CONDUCTOR MODELLING PROBLEM}

The first test of bus bar modelling made with FEM software has lead to critical shortcomings. The geometrical inhomogeneity and the necessity to mesh the air makes the nodes number of the problem unacceptable. Thus, some case studies have brought to use a modelling method that fit particularly well with this sort of problem. This method - based on the more general mathematical method called the Moments Method (MoM) - is called the Partial Element Equivalent Circuit (PEEC) method, and contains numerous by-products.

The Partial Element Equivalent Circuit - PEEC - model, introduce by A.E. Ruehli in the seventies, is widely used nowadays so as to obtain an electrical equivalent circuit of a set of conductors. This method extracts resistive $(R)$, mutual inductive $\left(L_{p}\right)$ and capacitive $(P)$ partial electrical elements. In its theoretical development the $\left(L_{p}, P, R\right)$ PEEC method takes into account the capacitive effect; however this effect is neglected in the basic $\left(L_{p}, R\right)$ PEEC model, mostly because it is much more delicate to implement.

The fundamental $\left(L_{p}, P, R\right)$ PEEC equation presented in 2 is introduce by A.E. Ruehli in [10] and [11]; this equation is based on the superposition of all the sources that create an electrical field in a conductor. The three right terms impliqued in 2 represent respectively the imposed electrical field $\mathbf{E}_{\mathbf{0}}$ (considered zero), the time derivative of the magnetic vector potential $\mathbf{A}$ and the gradient of the electric scalar potential $\phi$. After having discretized the conductors, the unknowns presents in 2 are the discrete current density disctribution $\mathbf{J}_{k}$ and the discrete charge den- sity distribution $\rho_{k}$.

$$
\mathbf{E}=\frac{\mathbf{J}}{\sigma}=\mathbf{E}_{0}-\frac{\partial \mathbf{A}}{\partial t}-\nabla \phi
$$

This last term, which is responsible for taking into account the capacitive effect, can be problematic for complex geometries [12] [13], or quite complex to implement [14]; thus, it is usually neglected in low frequencies applications modelling [15]. However, $\left(L_{p}, R\right)$ PEEC model yields incorrect predictions of damping or losses that occur at high frequencies or for obviously capacitive dominant systems. Anyway, variants of solvers for 2 exist so as to focus more specifically on one or other interesting physical phenomena intrinsic to the problem; for more details on existing applications see [11] [16] and [17].

Usually, the capacitive aspect (the $\nabla \phi$ in 2) is treated through the calculus of the coefficients of potentials matrix $P$ [12]. The coefficients of capacity matrix $C$ is deduced of $P$ by $C=P^{-1}$, and finally the capacitance matrix $C_{S}$ is extracted by the means of $C$ terms reorganisation (see [11] and [18]). The $C_{S}$ matrix terms represents each partial capacitance $c_{i j}$ between each nodes $i$ and $j$ created when the conductors are discretized. This approach remains very interesting (see authors publications) for medium to high frequency conductor modelling, until the aparition of retardation effects; then retardated PEEC (or advanced rPEEC [19]) models must be implemented. Whatever it may be, the $\left(L_{p}, R\right)$ PEEC modelling approach is well implanted for obtaining bus bar electrical equivalent model [15] [16].

The Fig. 6 show the 2D $\left(L_{p}, R\right)$ PEEC electrical equivalent model of the bus, constituted of only resistances and mutual inductances (the term $\nabla \phi$ of 2 is neglected). The 2D discretization has been set to $2 \times 2\left(n_{d}=2\right)$ for a better visibility. This model is accurate enough for low frequencies or non-capacitive system [7]. However the application presented is mainly capacitive and this essential aspect must appears in the model. Thus, the Fig. 7 presents a possible $\left(L_{p}, P, R\right)$ PEEC in which the non-facing partial elements partial capacity have been neglected.

Knowing with a reasonable precision the currents lines in the conductors leads to the local magnetic field. In fine all the electrical drive and the consequences of different faults on the whole system and on the DC bus bar local magnetic field signal signature are modelizable. Such a tool would provide significant advances in the on line monitoring, if coupled for instance with the patterns recognitions methods or other without-model-diagnostic methods.

\section{CONCLUSION}

This paper has presented an analysis of a DC bus bar (of a dozen $\mathrm{kW}$ inverter) magnetic field. The frequency 


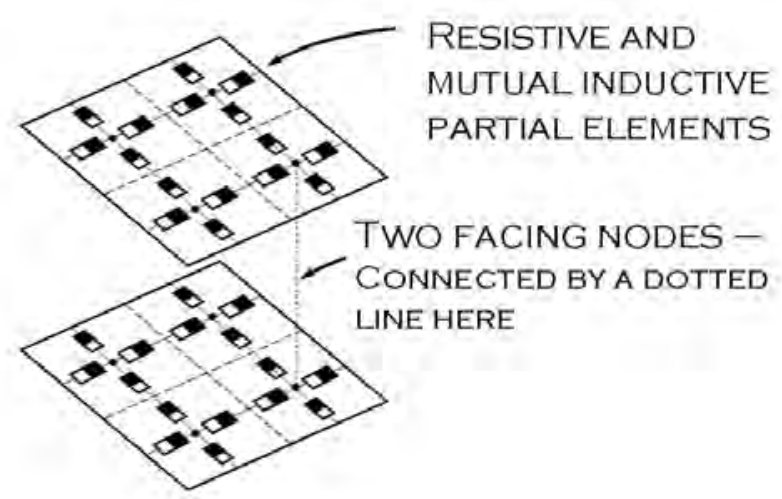

Fig. 6. The $\left(L_{p}, R\right)$ PEEC electrical equivalent model of a bus constitued of two thin conducticve plates facing each other.

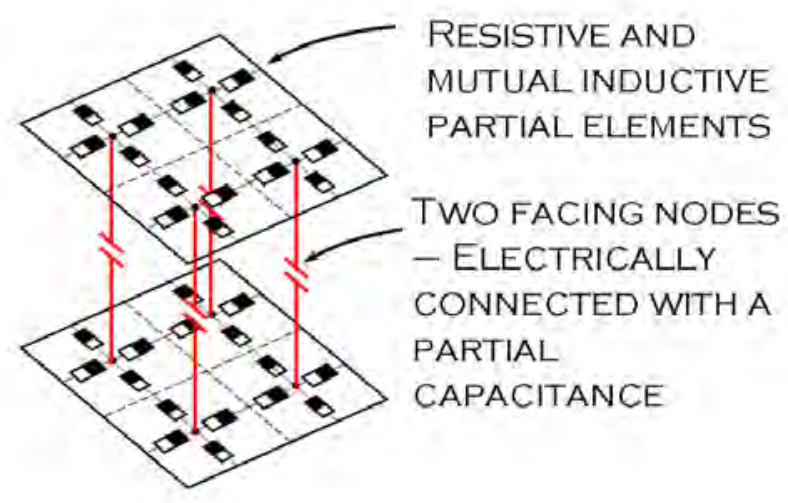

Fig. 7. A possible $\left(L_{p}, P, R\right)$ PEEC electrical equivalent model of the same bus in which the non-facing partial elements partial capacity have been neglected.

spectral analysis of this magnetic field measured at a specific place above the inverter DC bus provide significant signal signature. Information not only on the inverter but also on the induction machine and its load are presents. The amplitude of each harmonics is directly related to the measurement location and thus a reliable modelling of the structure would provide information for on line diagnosis methods. The EMF behaviour of the bus bar is studied with the Partial Element Equivalent Method. This method has made its proof and because of the electrical equivalent model obtained can be easily coupled with the electrical circuits modelling software; a whole electrical bench diagnosis is possible.

\section{REFERENCES}

[1] P. Vas. Parameter estimation, condition monitoring and diagnosis of electrical machines. Clarendron Press, Oxford, 1993.

[2] Schneider Electric. La Suret de Fonctionnement ( $\mathrm{S} d \mathrm{~F}$ ). Intersections, magazine Schneider Electric - Guide Technique, Novembre, 2004.

[3] M. Schroedl and R.S. Wieser. Emf-based rotor flux detection in induction motors using virtual short circuits. IEEE Transactions on Industry Applications, 34(1):142-147, 1998.

[4] G. Le Coat, A. Foggia, J.P. Bongiraud, and P. Le Thiec. Electromagnetic signature of induction machines. IEEE Transactions on Energy Conversion, 14(3):628-632, 1999.

[5] Z. Ye, B. Wu, and A.Sadeghian. Simulation of electrical faults of three phase induction motor drive system. In Proceeding of the 32nd Power Electronics Specialists Conference, PESC01, pages 75-80, Vancouver, 2001.

[6] J.L. Schanen, E. Clavel, and J. Roudet. Modeling of low inductive connections : the planar busbar structure. In Industry Applications Society Annual Meeting, Conference Record of the 1994 IEEE, pages 1246-1250, Denver, CO USA, 2-6 Octobre 1994.

[7] N. Piette, E. Clavel, and Y. Marechal. Optimization of cabling in power electronics structure using inductance calculation. In Proceeding of the IEEE Industry Application conference IAS98, pages 925928, New York, USA, 12-15 Octobre 1998

[8] J.M. Allocco. Laminated bus bars for power system interconnects. In Proceeding of the IEEE APEC conference, pages 585-589, New York, USA, 1997.

[9] R.R. Schoen and T. Habetler. Effects of time varying loads on rotor fault detection in induction machines. IEEE Transactions on Industry Applications, 31(4):900-906, 1995.

[10] A.E. Ruehli. Equivalent circuit models for three-dimentional multiconductor systems. IEEE Transactions on Microwave Theory and Techniques, 22(3):216-221, 1974.

[11] A.E. Ruehli and P.A. Brennan. Capacitance models for integrated circuit metallization wires. IEEE Journal of Solid-State Circuits, 10(6):530-536, 1975.

[12] A.E. Ruehli and H. Heeb. Circuit models for three-dimensional geometrices including dielectrics. IEEE Transactions on Microwave Theory and Techniques, 40(7):1507-1516, 1992.

[13] C.F. Wang, L.W. Li, P.S. Kooi, and M.S. Leong. Efficient capacitance computation for three-dimensional structure based on adaptative integral method. Progress In Electromagnetics Research, PIER, 30(1):33-46, 2001.

[14] J. Ekman, G. Antonini, and A. Orlandi. 3d peec capacitance calculations. IEEE Transactions on Antennas and Propagation, 46(12):1824$1832,1998$.

[15] J. Roudet, J.L. Schanen, and E. Clavel. Importance des interconnexions en lectronique de puissance. Revue Internationale de Gnie Electrique, 2(1):55-82, 1999.

[16] M. Besacier, J.M. Guichon, J.L. Schanen, and J. Roudet. Bus bar copper losses computation. The European Physical Journal, Applied Physics, 23(1):55-62, 2003.

[17] K.M. Coperich, A.E. Ruehli, and A. Cangellaris. Enhanced skin effect for partial-element-equivalent-circuit (peec) models. IEEE Transactions on Microwave Theory and Techniques, 48(9):1435-1442, 2000.

[18] Maxime Besacier. Adaptation de la methode PEEC la representation electrique des strucures d'electronique de puissance. Thse de doctorat, Institut National Polytechnique de Grenoble, LEG, 2001.

[19] Yi Cao, Zheng-Fan Li, Ji-Feng Mao, and Jun-Fa Mao. A peec with a new capacitance model for circuit simulation of interconnects and packaging structures. IEEE Transactions on Microwave Theory and Techniques, 48(2):281-287, 2000. 